\title{
RELATIONSHIP BETWEEN LACTATION AND POST-PARTUM UTERINE INVOLUTION IN SRIKANDI HUSADA CLINIC, KUDUS, CENTRAL JAVA
}

\author{
Noor Hidayah
}

School of Health Sciences (STIKES) Muhammadiyah, Kudus

\begin{abstract}
BACKGROUND: Rapid uterine involution prevents post-partum hemorrhage. Lactation stimulates the release of oxytocin hormone that can be used to enhance uterus contraction. This study aimed to analyze the relationship between lactation and post-partum uterine involution.

SUBJECT AND METHODS: This was a cross sectional study, conducted from January to November 2014, in Kudus, Central Java. A sample of 30 post-partum mothers was selected from Srikandi Husada Clinic, Kudus, Central Java. The dependent variable was post-partum uterine involution. The independent variable was lactation. The data was analyzed using Odds Ratio and Chi Square.

RESULTS: There was positive relationship between lactation and normal uterine involution, although it was not statistically significant. Lactating mothers were 5.71 times more likely to have normal uterine involution than non lactating mothers $(\mathrm{OR}=5.71 ; 95 \% \mathrm{CI}=0.44$ to $7.18 ; \mathrm{p}=0.144)$.
\end{abstract}

CONCLUSION: It is advised that postpartum mothers increase lactation to enhance uterine involution.

Keywords: postpartum, lactation, uterine involution 